\title{
Can Genetic Factors Explain the Spillover of Warmth and Negativity Across Family Relationships?
}

\author{
Jody M. Ganiban, ${ }^{1,2}$ Erica L. Spotts, ${ }^{2,3}$ Paul Lichtenstein, ${ }^{4}$ Gagan S. Khera,' David Reiss, ${ }^{2}$ \\ and Jenae M. Neiderhiser ${ }^{2}$ \\ 'Department of Psychology, George Washington University, Washington, United States of America \\ ${ }^{2}$ Center for Family Research, Department of Psychiatry and Behavioral Sciences, George Washington University, Washington, \\ United States of America \\ ${ }^{3}$ Behavioral and Social Research Program, National Institute on Aging, Bethesda, Maryland, United States of America \\ ${ }^{4}$ Department of Medical Epidemiology and Biostatistics, Karolinska Institutet, Stockholm, Sweden
}

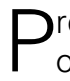
revious studies indicate that the emotional quality of marital relationships is mirrored in parent-child relationships. We explored the degree to which these associations are explained by genetic and environmental factors. Participants were drawn from the Twin and Offspring Study in Sweden (TOSS), and included 544 female twin pairs (258 monozygotic [MZ], 286 dizygotic [DZ]), and 311 male twin pairs (128 MZ, $183 \mathrm{DZ}$ ). The spouses and one adolescent child of each twin also participated in this study. The twins completed self-report measures that assessed their marital quality and their warmth and negativity towards their children. Observational ratings of marital warmth and negativity, and of maternal warmth and negativity were obtained for a subset of female twin pairs (150 MZ, 176 DZ). Selfreported marital satisfaction was associated with self-reported parental warmth and negativity for mothers $(r s=.25,-.36)$ and fathers $(r s=.25,-.44)$. For the observational measures, marital warmth was associated with maternal warmth $(r=.42)$, while marital negativity was associated with maternal negativity $(r=.34)$. On average genetic factors explained nearly half of the covariance between selfreported marital satisfaction and parenting for mothers $(48 \%)$ and fathers (47\%). Genetic factors explained $21 \%$ of the covariance between observed marital and maternal warmth, but did not contribute to associations between marital and maternal negativity. These findings indicate that parents' genetically influenced characteristics help shape the emotional climate of the family.

Over 3 decades of research have recognized that relationships within families affect each other. Of particular interest have been associations between parents' marital relationship and parent-child relationships. Previous studies report consistent associations between the parents' perceptions of the marital relationship, the presence of marital conflict, and parenting behaviors. In a meta-analysis of 68 studies, Erel and Burman (1995) found that on average, associations between indices of marital quality and parenting were moderate in magnitude. In a more recent meta-analysis, Krishnakumar and Buehler (2000) focused exclusively upon associations between marital conflict and indices of negative parenting (harsh discipline, lax control) and positive parenting styles (supportiveness and control). Similar to the earlier meta-analysis, high levels of marital conflict were correlated with greater use of harsh discipline and lower parental support.

Although these associations are well established, the underlying mechanisms are not entirely clear. Current theories emphasize environmental mechanisms to explain consistencies in the expression of positive and negative affect across family relationships. For example, one predominant theory proposes that highly conflictual or poor quality marriages place emotional stress on parents, leading to deterioration in parenting quality (e.g., Easterbrooks \& Emde, 1988). A second explanation is that emotions and behaviors from one relationship are transferred to other family relationships (Margolin et al., 1996). Although both views articulate different mechanisms, they both propose that emotions and behaviors that arise within one family relationship 'spill over' to other family relationships, causing similarities amongst all family relationships (Cox \& Paley, 1997). However, part of the convergence between family relationships may be driven by the characteristics of the individuals involved, rather than by the spill over of emotions. Consistent with this interpretation,

Received 30 October 2006; accepted 27 January 2007.

Address for correspondence: Jody M. Ganiban, Department of Psychology, 2125 G St., N.W, George Washington University, Washington, DC 20052, USA.E-mail: ganiban@gwu.edu 
previous studies indicate that genetically influenced characteristics such as neuroticism and extraversion are associated with both marital satisfaction and parenting (Jockin et al., 1996; Kochanska et al., 2004).

It is extraordinarily difficult to disentangle the impact of individuals on relationships from the effects of relationships on individuals. However, twin research can help identify person-based effects on relationships by estimating the contributions of genetic factors to variations in relationships as well as associations between different relationships. To further understand why marital quality and parent-child relationships are related, we explored the degree to which covariance between marital relationships and parent-child relationships are explained by genetic and experiential factors, and whether these contributions vary by the relationship dimension studied. The answers to these questions have implications for understanding the mechanisms that underlie such associations, as well as for family interventions. For example, if, indeed, a stressful marriage causes more negative parenting due to the emotional stress it places upon a parent, then improvements in marriage should be followed by improvements in the parent-child relationship. However, if genetically influenced characteristics such as personality primarily account for associations between marital quality and parenting, then even successful marital interventions are not expected to spill over to the entire family. Within such targeted interventions, parents may learn specific strategies for managing issues pertaining to the marriage, but these strategies may not be useful for modulating emotions and behaviors that arise during interactions with their children.

Several studies indicate that genetic factors contribute to parenting and to the marital relationship. Most behavioral genetic studies on parenting have utilized child-based designs in which estimates of genetic and environmental contributions to parenting reflect the children's genes and experiences, rather than the parents' (Towers et al., 2001). However, the smaller body of research that has utilized parent-based designs generally detected moderate genetic contributions to parental warmth and support (Kendler, 1996; Losoya et al., 1997; Perusse et al., 1994; Spinath \& O'Connor, 2003). Genetic contributions to parental negativity tend to be lower than for parental warmth (Losoya et al., 1997), or nonsignificant (Spinath \& O'Connor, 2003). Consistent with these findings, an earlier report from the Twin and Offspring Study in Sweden (TOSS) detected significant genetic contributions to maternal positivity, whether self-, spouse-, or child-reports were examined with heritability estimates $\left(b^{2}\right)$ ranging from $23 \%$ to $45 \%$ (Neiderhiser et al., 2004). In contrast, within TOSS, genetic contributions to maternal negativity were high for self-reported maternal negativity $\left(h^{2}=39 \%\right)$, but negligible for child $\left(b^{2}=5 \%\right)$ and observational reports $\left(b^{2}=0\right)$.

Previous research has also detected genetic contributions to marital quality. For example, divorce has been found to be moderately heritable for women $\left(b^{2}=59 \%\right)$ and for men $\left(b^{2}=55 \%\right.$; Jockin et al., 1996). An additional study that focused upon male veterans reported significant genetic contributions to long-term pair bonding ( $b^{2} \mathrm{~s} 31$ to $42 \%$ ), and marriage instability $\left(b^{2} \mathrm{~s} 22 \%\right.$ to $28 \%$; Trumbetta \& Gottesman, 2000). Lastly, a previous report from TOSS detected significant genetic contributions to specific marriage indicators, including marital satisfaction $\left(b^{2}=28 \%\right)$, dyadic cohesion $\left(b^{2}=24 \%\right)$, and dyadic consensus $\left(b^{2}=33 \%\right.$; Spotts et al., 2004). Shared environmental contributions were negligible, while nonshared environmental factors explained most of the remaining variance. More recently, Spotts and colleagues (2005) used multiple self-report measures of the marital relationship to create a composite measure of marital satisfaction, and observational scales to create marital warmth and conflict composites. These analyses also indicated significant genetic contributions to positive indicators of the marital relationship, whether selfreport or observational measures were used $\left(b^{2} s 21 \%\right.$ to $35 \%$ ).

In summary, significant associations between marital quality and parenting are most frequently interpreted within a causal framework - emotions and behavior from one relationship spill over to other family relationships (e.g., Cox \& Paley, 1997; Erel \& Burman, 1995). However, previous studies also indicate that genetic factors contribute to parent-child and marital relationships, and raise the possibility that person-based factors explain associations between both relationships. Therefore, a primary objective of the current study was to examine whether genetic factors account for similarities in the emotional tone of both family relationships. A second objective of this study was to examine whether genetic and environmental contributions to associations between marriage and parenting differ for positive and negative aspects of relationships.

\section{$\overline{\text { Method }}$ \\ Participants}

TOSS included 909 same-sex twin pairs who were recruited through the Swedish Twin Registry (Lichtenstein et al., 2002). TOSS included two cohorts. Cohort 1 was comprised of 326 female twin pairs, and Cohort 2 included an additional 583 female and male twin pairs. Both cohorts had the same inclusion criteria: each twin had to (1) have an adolescent child who was the same gender and within 4 years of age as the his/her co-twin's child, and (2) be involved in a long-term relationship with a partner who resided in the same home. These inclusion criteria were adopted to ensure that the current living experiences of each of the twin parents was comparable to his or her co-twin (see Reiss et al., 2001, for a detailed description of the sample and study rationale for Cohort 1). The current study included 855 twin pairs whose zygosity was known, and had complete marital 
and parenting data. This sample consisted of 544 female twin pairs (258 monozygotic [MZ] and 286 dizygotic pairs [DZ]), and 311 male twin pairs (128 $\mathrm{MZ}$ and $183 \mathrm{DZ}$ pairs). The average age of the twin mothers was $43.6( \pm 4.6)$ years. Their children ranged in age from 11 to 22 years (mean child age $=15.7 \pm$ 2.4 years), and $49 \%$ were male. The $\mathrm{MZ}$ and $\mathrm{DZ}$ twin women were not significantly different in age, occupation level, education or in regard to the age or gender of their children, or the age of their partners.

Zygosity assignment was initially based upon the extent to which twins viewed themselves as 'similar as two berries'. If both members of a pair viewed themselves as similar, they were classified as MZ twins, if both responded 'not alike' they were classified as DZ twins. If the twins did not agree, they were asked if strangers have a difficult time telling them apart. If both individuals of a pair responded 'almost always or always' or 'often' they were classified as MZ twins. If both responded 'seldom' or 'almost never or never', they were classified as DZ twins. Zygosity assignment was confirmed for most of the sample via genotyping.

\section{Procedures}

All participants in TOSS were mailed questionnaire packets prior to the home visit (Reiss et al., 2001). The spouses and children of each twin parent also were sent a questionnaire packet. The specific questionnaires assessed various aspects of current adjustment and functioning, personality, mental health, and family relationships. During the home visit, family members were asked to complete a variety of questionnaires that assessed family relationships.

Cohort 1 participants were also videotaped during a 10-minute interaction with their spouse, and during a separate 10-minute interaction with their children. Ten-minute interactions between the twin's spouse and child were also videotaped. For each interaction the interviewer selected three topics of conflict that had been identified previously by members of each potential dyad (i.e., mother-father, mother-child, fatherchild), and asked them to discuss these topics for 10 minutes. The order in which the dyads were videotaped was random. The current study only utilized the marital and mother-child interactions.

\section{Measures}

Parenting and the quality of marital relationships were assessed by an extensive battery of self-report measures and behavioral observations. Whenever possible, measures that had already been used in Sweden were administered. A description of the translation process can be found in Reiss et al. (2001).

\section{Self-Reported Parenting}

A series of self-report measures were used to assess the women's perceptions of their parenting behavior. All of the self-report measures, save one (Expressed Emotion), were derived from Hetherington and Clingempeel's (1992) study of stepfamilies and used in the Nonshared Environment and Adolescent Development project (NEAD; Reiss et al., 2000). Each questionnaire is described below.

The Expression of Affection Inventory (Hetherington \& Clingempeel, 1992) assessed the degree to which expressive and instrumental affection is exhibited by parents and children. Although this questionnaire was completed by the twins, their spouses and children, only the twins' ratings were used in the current study. Alphas were high for expressive affection (alpha $=.85$ ) and for instrumental affection (alpha $=.80)$.

The Expressed Emotion Scale (Hansson \& Jarbin, 1997) assessed the levels of perceived criticism, critical remarks, and emotional overinvolvement within the parent-child relationship. Reliabilities for the twin mothers and fathers for the specific subscales were alpha $=.68$ for criticism, alpha $=.87$ for critical remarks, and alpha $=.72$ for overinvolvement.

The Parent-Child Relationships Scale (PCR) assessed closeness and conflict between the parent and the child using two scales of the same names. Reliability for the twin mothers and fathers were adequate for the conflict (alpha $=.68$ ) and closeness $($ alpha $=.82)$ scales.

The Child Monitoring Scale measured the extent to which parents are informed about (knowledge), try to control (attempted control), and are successful in controlling (actual control) their children's activities. Each subscale demonstrated adequate reliability: knowledge $($ alpha $=.89)$, attempted control $($ alpha $=.87)$, and actual control (alpha $=.91)$.

The Child Rearing Issues Scale assessed parent's use of communication and reasoning, punitive discipline, and permissive discipline with their children. Alphas for these subscales were .91 for communication and reasoning, .82 for punitive discipline, and .73 for permissive discipline.

The Child Rearing Issues on Parent-Child Agreement scale assessed the extent to which parents and children agree on different issues, including: household effects, behavior to others, adolescent issues, deviant behavior. This measure also includes a summary scale of total disagreements. Internal reliabilities were adequate for all subscales, household effects (alpha $=.85)$, behavior to another (alpha $=.78)$, adolescent issues (alpha $=.71)$, deviant behavior (alpha $=.56)$, and total disagreements (alpha $=.89)$. For the purposes on this study, only the total disagreement scale was used.

\section{Self-Reported Marital Quality}

Several measures were used to assess marital quality. The Dyadic Adjustment Scale (Spanier, 1976) is frequently used to assess the quality of marital relationships and similar dyads. This measure was designed to be used on married and unmarried couples, and has been previously used with Swedish samples (Kaslow et al., 1994). The alpha for the total dyadic adjustment scale was .70. 
The Expressed Emotion Scale (Hansson \& Jarbin, 1997) assessed levels of perceived criticism, critical remarks and emotional overinvolvement within the marital relationship. The alphas for this sample were $.79, .88$, and .72 , respectively

Lastly, one item from the Marital Instability Scale (Booth et al., 1983) asked whether the respondent had discussed divorce or separation with a friend.

\section{Videotaped Interactions}

Twins in Cohort 1 were videotaped as they interacted with their spouses and their children. The videotaped interactions were rated using the Family Interaction Coding System (Hetherington et al., 1992). Independent coders rated each member of a twin pair, and independent coders rated mother-child and marital interactions. Fourteen five-point rating scales from the original coding scheme were used to assess the twins' behaviors as they interacted with their spouses and children: anger, warmth, coercion, assertiveness, involvement, self-disclosure, communication, authority/control, depressed mood, positive mood, problem solving, transactional conflict, sociability, and antisociability. Four additional subscales were developed for TOSS, and were coded for all family members: comprehensibility, manageability, meaningfulness, and sympathy. Lastly, some subscales were used for specific dyads. Monitoring and attempted parenting were rated within the parent-child interactions, while negative/positive atmosphere, disgust/contempt, defensiveness, and withdrawal were rated in the marital interactions. Interrater reliabilities were generally high (kappas ranged from .60 to .79$)$.

\section{Data Analysis}

\section{Creation of Composite Scores}

In the interest of data reduction, factor analysis was used to generate composites for marital quality and parenting. Factor analysis of the marital quality measures for Cohort 1 yielded three factors: self-reported marital satisfaction, observed marital conflict, and observed marital warmth (Spotts et al., 2005). The marital satisfaction factor included self-report measures indicative of marital satisfaction, affection, and consensus versus criticism and perceived instability. This factor was replicated in cohort 2 for the male and female twins and their spouses. The observed marital conflict factor related to the degree to which the women demonstrated anger or coercion towards their spouses versus affection and positive affect during the problem solving tasks. The observed marital warmth factor reflected the extent to which the women communicated with and demonstrated warmth and positive affect towards their spouse versus being withdrawn during the problem solving tasks.

Parenting composites for cohort 1 have been reported in a previous paper (Neiderhiser et al., 2004). However, those composites did not include the Expressed Emotion measure. The current study used composites generated from a factor analysis that included cohorts 1 and 2 of TOSS and the Expressed Emotion measure (Ulbricht et al., 2006). This analysis yielded three factors for the twin mothers and fathers: parental negativity, warmth, and control. Self-reported parental negativity reflected the degree to which parents described themselves to be punitive or ineffectual in their discipline, and their perceptions of conflict within the relationship. Self-reported parental warmth reflected the degree to which parents described warmth and positive affect within their relationship with their children. Because this study focused upon affective components of family relationships, only parental negativity and warmth were included in subsequent analyses. Factor analyses based upon the observed parenting variables also yielded three factors: observed maternal negativity, observed maternal warmth, and observed maternal control (Neiderhiser et al., 2004). Observed negativity reflected the degree to which conflict and anger were present during mother-child interactions, while observed maternal warmth reflected the expression of positive affect and responsiveness within the motherchild interaction. Because the current study focused upon similarities in the emotional quality of marital and parent-child relationships, the third composite, maternal control, was not included in analyses.

\section{Preliminary Analyses}

Prior to analyses, the effects of maternal age, child age, child gender, and child gender $\mathrm{x}$ age interaction were residualized from all variables. These factors have been associated with parenting and children's behaviors, and thus, presented potential confounds to assessments of linkages between marital and parenting behaviors (McGue \& Bouchard, 1984). Next, to minimize the impact of outliers, the data were ranked ordered (Eaves et al., 1997).

\section{Univariate Analyses: Estimating Genetic and Environmental Contributions to Parenting and Marital Quality}

Previous reports from TOSS have estimated genetic and environmental contributions to marital quality and parenting. However, these reports only included Cohort 1 , used slightly different composites, or did not statistically control for children's age and gender (Neiderhiser et al., 2004; Spotts, et al., 2005). Consequently, biometric model-fitting was employed to estimate additive genetic (A), shared environmental (C) and nonshared environmental (E) contributions to the marital and parenting composites. The specific model used is depicted in Figure 1. Because TOSS included only adult twins, shared environmental factors most likely reflect experiences the co-twins shared during their childhood, when they lived together. However, it is also possible that shared environmental factors include more contemporary experiences reflective of the degree of contact the twins currently have with each other. The nonshared environmental factor encompasses experiences that 


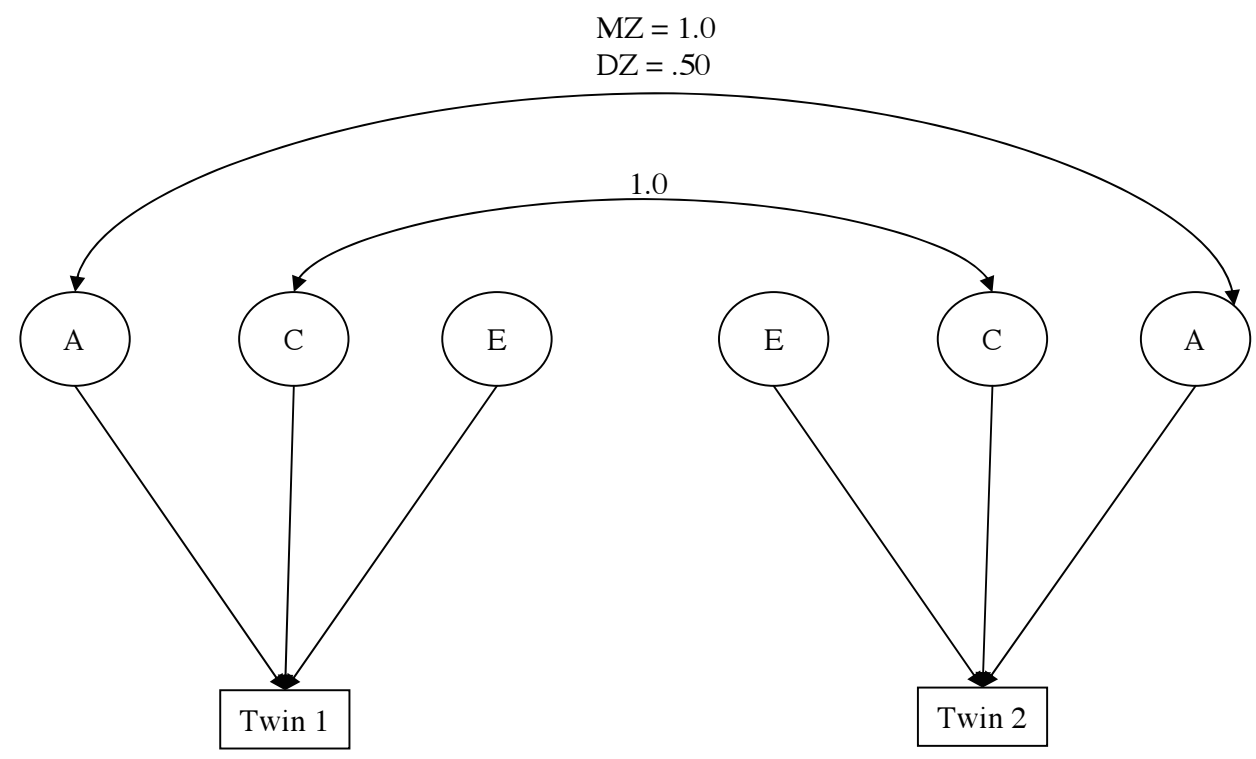

Figure 1

Univariate quantitative genetic model. Genetic influences are represented by A, shared or 'common' environmental influences by $C$ and nonshared environmental influences by $E$. The correlation between $A$ for the twin pairs varies based on the degree of genetic relatedness. Because $C$ represents nongenetic influences that make twins similar to one another, this path is set to 1.0. Nonshared environmental influences $(E)$ are uncorrelated and contain measurement error.

make the co-twins different from each other as well as measurement error.

As depicted in Figure 1, three paths were set to fixed values. Because MZ twins share the same genotype, while DZ twins share approximately $50 \%$ of the same segregating genes, the path from A for Twin 1 to A for Twin 2 was set to 1.0 for MZ twins, and to .50 for DZ twins. The path between C for Twins 1 and 2 was also set at 1.0, reflecting that the shared environment factor encompasses experiences common to both twins. The path between $\mathrm{E}$ for Twins 1 and 2 was set to ' 0 ' because, by definition, nonshared environmental factors consist of experiences that are unique to each twin. Lastly, the Twin 1's and Twin 2's paths were constrained to be equal. Mx (Neale, 2000) was used to compute parameter estimates and confidence intervals for the model.

Model fit was assessed via $\chi^{2}$ and the Akaike Information Criteria (AIC; Tanaka, 1993). When the $\chi^{2}$ is nonsignificant, the model accurately represents the data. However, $\chi^{2}$ values are also likely to reject a model that fits the data well, but imperfectly, are highly sensitive to sample size, and will improve when more parameters are added to the model (Mulaik et al., 1989; Neale \& Cardon, 1992), thus, additional indices are often used in combination with $\chi^{2}$. One such measure is the Akaike's Information Criterion (AIC; Tanaka, 1993), which assesses the fit of the model relative to its degrees of freedom. A low or negative AIC value indicates a more optimal balance of explanatory power and parsimony. The model depicted in Figure 1 was further refined by removing latent factors that did not account for significant variance in a target variable. A latent variable was considered to be nonsignificant if its elimination from the model did not worsen the fit of the model. The fits of these nested models relative to the full model were determined by computing the difference in $\chi^{2}$ values between the nested and full model. If it was necessary to compare the appropriateness of two models with equivalent degrees of freedom, then the AIC was used to identify the better model.

\section{Bivariate Analyses: Estimating Genetic and Environmental Contributions to Associations Between Marital Quality and Parenting}

Bivariate analyses addressed the degree to which marital quality and parenting variables were associated and the extent to which these associations were explained by genetic and environmental factors. In the latter analyses, covariance between marital quality and parenting was partitioned into genetic, shared environmental, and nonshared environmental components. Consequently, if marital quality and parenting variables were moderately correlated (i.e., $r$ greater than .20), they were included in these analyses.

As depicted in Figure 2, a Cholesky model was used to assess the relationship between marital satisfaction and parenting. This model was chosen because it permitted estimation of the degree to which genetic and environmental factors associated with marital satisfaction explained its covariance with parenting. This model included latent genetic (A1), shared environmental (C1), and nonshared environmental (E1) factors that explain associations between the marital relationship and parenting variables. In addition, latent genetic (A2), shared environmental (C2), and nonshared environmental (E2) factors that explained unique variance in mothering were 


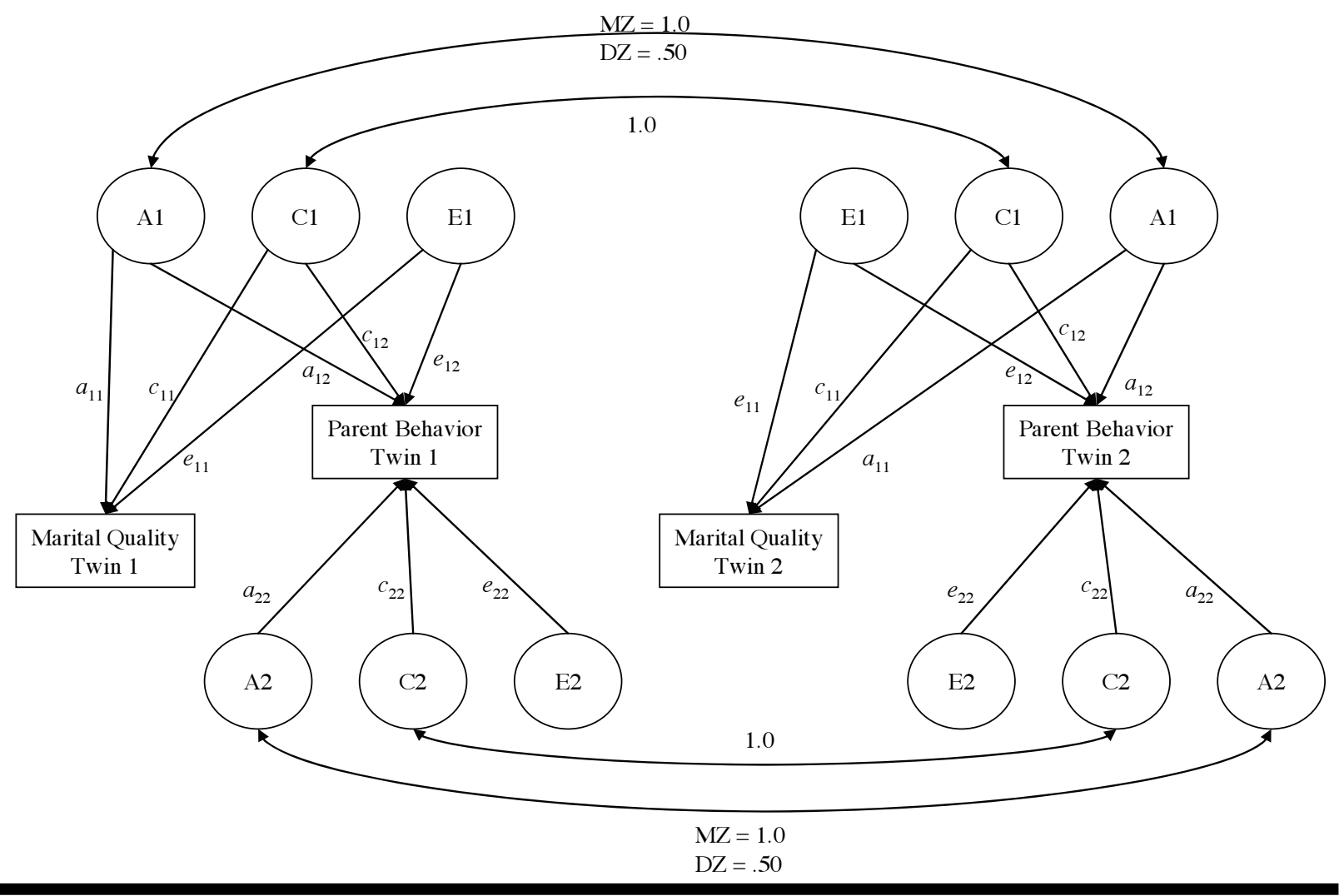

Figure 2

Bivariate quantitative genetic model. Genetic influences are represented by $A$, shared or 'common' environmental influences by $C$ and nonshared environmental influences by $E$. The correlation between $A$ for the twin pairs varies based on the degree of genetic relatedness. Because $C$ represents nongenetic influences that make twins similar to one another, this path is set to 1.0. Nonshared environmental influences (E) are uncorrelated and contain measurement error.

also included in the model. The Cholesky model in Figure 2 was refined by eliminating paths that were not significant in the univariate analyses.

The path estimates of the best fitting models were used to assess genetic and environmental contributions to covariance between marital satisfaction and parenting. The total association $\left(r_{\text {est }}\right)$ between marital quality and parenting was estimated by multiplying and then summing the paths that linked each variable to the latent variables $\mathrm{A} 1, \mathrm{C} 1$, and $\mathrm{E} 1, r_{\mathrm{est}}=a_{11} \times a_{12}+c_{11} \times c_{12}+e_{11} \times$ $e_{12}$. The proportion of the total association that was mediated by A1 was computed as $\left(a_{11} \times a_{12}\right) / r_{\text {est }}$, while the proportions of the association mediated by $\mathrm{C} 1$ and $\mathrm{E} 1$ were computed as $\left(c_{11} \times c_{21}\right) / r_{\text {est }}$ and $\left(e_{11} \times e_{21}\right) / r_{\text {ess }}$, respectively. Similar to the univariate analyses, paths between genetic factors were set to 1.0 for MZ co-twins, and .50 for DZ co-twins. For all co-twins, shared environment and nonshared environment paths were set at 1.0 and 0.0 , respectively. The remaining paths were estimated, but were constrained to be equal for Twins 1 and 2 .

\section{Results}

\section{Univariate Analyses}

The fit indices for the full ACE model and nested models for each parenting and marital satisfaction composite are summarized in Table 1. For mothers, the best fitting and most parsimonious model for maternal negativity was the AE model. In this case, elimination of $\mathrm{C}$ did not alter the $\chi^{2}$ value for the model. Elimination of A, however, led to a significantly worse model fit $\left(\Delta \chi^{2}(1)=8.44, p<.05\right)$. The findings for maternal warmth and marital satisfaction were less clear-cut. Elimination of $\mathrm{C}$ did not affect the $\chi^{2}$ value for the maternal warmth or marital satisfaction models. Elimination of A led to higher $\chi^{2}$ values for both variables, but these increases did not reach statistical significance. Lastly, elimination of both A and C simultaneously yielded poor-fitting models, for example, for maternal warmth $\left(\Delta \chi^{2}(2)=62.07\right.$, $p<.05)$, and marital satisfaction $\left(\Delta \chi^{2}(2)=36.09\right.$, $p<.05)$. These latter findings suggest that there are familial contributions to both variables, but there is not sufficient power in the univariate model to distinguish the relative importance of $\mathrm{C}$ and $\mathrm{A}$. Nevertheless, the AE model was selected as the best fitting and most parsimonious model for marital warmth and satisfaction because it had the lowest $\chi^{2}$ and AIC values in each instance. The estimates for these models are included in Table 2. 
Table 1

Fit Indices for the ACE Model and Nested Models for Self-Reported Marital Quality and Parenting for Twin Mothers and Fathers

\begin{tabular}{|c|c|c|c|c|}
\hline Composite & Model & $d f$ & $\chi^{2}$ & AIC \\
\hline \multicolumn{5}{|l|}{ Mothers } \\
\hline \multirow[t]{4}{*}{ Maternal warmth } & ACE & 3 & 8.34 & 2.34 \\
\hline & $A E$ & 4 & 8.34 & -0.34 \\
\hline & CE & 4 & 10.93 & 2.93 \\
\hline & $\mathrm{E}$ & 5 & 70.41 & 60.41 \\
\hline \multirow[t]{3}{*}{ Maternal negativity } & ACE & 3 & 7.08 & 1.08 \\
\hline & $A E$ & 4 & 7.08 & -0.92 \\
\hline & CE & 4 & 15.52 & 7.52 \\
\hline \multirow[t]{4}{*}{ Marital satisfaction } & ACE & 3 & 2.01 & -3.99 \\
\hline & $A E$ & 4 & 2.01 & -5.99 \\
\hline & CE & 4 & 3.10 & -4.90 \\
\hline & $\mathrm{E}$ & 5 & 38.10 & 28.10 \\
\hline \multicolumn{5}{|l|}{ Fathers } \\
\hline \multirow[t]{4}{*}{ Paternal warmth } & ACE & 3 & 3.31 & -2.69 \\
\hline & $\mathrm{AE}$ & 4 & 3.31 & -4.69 \\
\hline & $C E$ & 4 & .89 & -7.10 \\
\hline & $\mathrm{E}$ & 5 & 31.47 & 21.47 \\
\hline \multirow[t]{3}{*}{ Paternal negativity } & ACE & 3 & 6.88 & 0.88 \\
\hline & $A E$ & 4 & 6.88 & -1.12 \\
\hline & CE & 4 & 13.03 & 5.03 \\
\hline \multirow[t]{4}{*}{ Marital satisfaction } & ACE & 3 & 2.33 & -3.67 \\
\hline & $A E$ & 4 & 2.33 & -5.67 \\
\hline & CE & 4 & 5.63 & -2.37 \\
\hline & $E$ & 5 & 11.59 & 1.60 \\
\hline
\end{tabular}

Note: ${ }^{*} p<.05 ;$ The best fitting and most parsimonious models are italicized.

Similarly, for paternal negativity, the best fitting model was the AE model as elimination of $\mathrm{C}$ did not affect the fit of the model, while elimination of A led to a significantly worse model fit $\left(\Delta \chi^{2}(1)=6.15\right.$, $p<.05)$. However, the relative importance of $\mathrm{A}$ and $\mathrm{C}$ were more ambiguous for paternal warmth and marital satisfaction. Elimination of $\mathrm{C}$ did not affect the fits of each model. In contrast, elimination of A slightly worsened the model fit for fathers' marital satisfaction $\left(\Delta \chi^{2}(1)=3.3, p<.10\right)$, and improved the model fit for paternal warmth $\left(\Delta \chi^{2}(1)=2.4, n s\right)$. Based upon these findings, the AE model was selected as the best fitting and most parsimonious model for fathers' marital satisfaction (see Table 2). A third model for paternal warmth that only included $\mathrm{E}$ was also tested. This latter model represented a significantly worse model fit than the full ACE model $\left(\Delta \chi^{2}(2)=28.16\right.$, $p<.05)$, suggesting that there are familial influences on paternal warmth, but, again, that there is insufficient power to determine if these influences reflect additive genetic or shared environment effects. Nevertheless, the fit indices indicated that the CE model represented a better fit to the data than the AE model. Consequently, the parameter estimates for this model are presented in Table 2.

Table 2 includes the parameter estimates for the best fitting models for self-reported parenting and for marital quality for the twin mothers and fathers. For mothers, genetic factors (A) explained $32 \%$ to $41 \%$ of variance for these variables. For fathers, the range was greater and genetic factors (A) explained $0 \%$ to $45 \%$ of the variance for these variables. In most cases, the remaining nonshared environmental factors (E) accounted for the remaining variance in the study variables.

The observational data for Cohort 1 mothers yielded a different pattern of findings (see Table 3 ). In two of the four variables examined (marital warmth and maternal warmth), there was a tendency for the reduced AE model to be a better, more parsimonious fit to the data than the full ACE model. In each case, removal of A from the model (i.e., the CE model) led to worse model fit, but these changes did not reach statistical significance for observed maternal warmth $\Delta \chi^{2}(1)=2.21$, or for observed marital warmth $\Delta \chi^{2}(1)=2.8, p<.10$. Removal of $\mathrm{C}$ in each case did not alter the $\chi^{2}$ values, suggesting that its contributions were negligible. However, the simultaneous elimination of $\mathrm{A}$ and $\mathrm{C}$ significantly worsened model fit: for example, for observed maternal warmth $\Delta \chi^{2}(2)=6.29$, $p<.05$; for observed marital warmth $\Delta \chi^{2}(2)=6.61$, $p<.05$. Consequently, the most parsimonious and best fitting model for both variables appeared to be the AE model. 
Table 2

Genetic and Environmental Contributions to Self-Reported Parenting and Marital Quality for Twin Mothers and Twin Fathers

\begin{tabular}{lccc}
\hline Measure & \multicolumn{3}{c}{ Estimates (CI) } \\
\hline \multicolumn{1}{c}{$\mathrm{A}^{2}$} & $\mathrm{C}^{2}$ & $\mathrm{E}^{2}$ \\
\hline Mothers & & & \\
Maternal warmth & $.41(.32-.50)$ & - & $.59(.50-.68)$ \\
Maternal negativity & $.36(.26-.45)$ & - & $.64(.55-.74)$ \\
Marital satisfaction & $.32(.22-.42)$ & - & $.68(.58-.78)$ \\
Fathers & & & \\
Paternal warmth & - & $.30(.20-.40)$ & $.62(.50-.75)$ \\
Paternal negativity & $.45(.32-.56)$ & - & $.55(.44-.68)$ \\
Marital satisfaction & $.23(.08-.37)$ & $.70(.60-.80)$ & $.77(.63-.92)$ \\
\hline
\end{tabular}

The best-fitting and most parsimonious model for observed maternal negativity was the CE model. For this variable, elimination of $\mathrm{C}$ led to a slightly worse model fit $\left(\Delta \chi^{2}(1)=1.01, n s\right)$, while elimination of $\mathrm{A}$ had no effect at all. However, simultaneous elimination of $\mathrm{A}$ and $\mathrm{C}$ led to a worse model fit, when compared to the full ACE model $\left(\Delta \chi^{2}(2)=11.61, p<\right.$ $.05)$. Lastly, for observed marital conflict, neither A nor $\mathrm{C}$ were found to account for significant variance, and their joint elimination did not negatively influence the fit of the model $\left(\Delta \chi^{2}(2)=.90, n s\right)$. Consequently, variance in observed marital conflict seemed best explained by nonshared environmental factors $(\mathrm{E})$.

The estimates for the best fitting models for the observational data are included in Table 4. For twin mothers, genetic factors only accounted for a small portion of variance in observed maternal warmth $(18 \%)$ and observed marital warmth $(18 \%$; See Table 4$)$. The remaining variance was related to nonshared environmental factors. Lastly, nonshared environmental factors primarily explained variance in both observed maternal negativity and marital negativity.

\section{Bivariate Analyses}

The correlations amongst all of the marital and maternal relationship composites are displayed in Table 5 . Significant correlations were detected for self-reported marital satisfaction and parenting. In general, more marital satisfaction was associated with more parental warmth, and less parental negativity. The magnitudes of these associations were greater than .20, and similar for mothers and fathers. In addition, a subset of mothers was observed during interactions with their spouse and with their children. Observed marital warmth was associated with observed maternal warmth, and observed marital conflict was associated with observed maternal negativity. Because we were primarily interested in examining the spill over of emotions across relationships, subsequent analyses focused upon associations between indices of positive marital and parental dimensions, and between negative marital and parental dimensions.

The univariate analyses tended to support an $\mathrm{AE}$ model for most of the study variables. However, these analyses were underpowered for self-reported parental warmth and marital satisfaction, and the relative contributions of shared environmental (C) and nonshared environmental (E) factors to these variables were difficult to distinguish. Because the bivariate Cholesky model contains more information, it has more power to differentiate between the contributions of $\mathrm{A}$ and $\mathrm{C}$ to variance in marital satisfaction and parenting than the univariate model. Therefore, the explanatory power and parsimony of the $\mathrm{AE}$ and $\mathrm{CE}$ bivariate models that included self-reported parental warmth and marital satisfaction were compared. Since these models had equivalent degrees of freedom, the model with the lowest $\chi^{2}$ and AIC values was identified as the best fitting and most parsimonious model.

\section{Self-Report Measures}

Mothers' marital dissatisfaction and maternal negativity. The $\mathrm{AE}$ model represented a better relative fit to the data $\left(\chi^{2}(14)=17.70, \mathrm{AIC}=-10.30\right)$ than the $\mathrm{CE}$ model $\left(\chi^{2}(14)=27.94\right.$, AIC $\left.=-.06\right)$. The parameter estimates for the AE model are summarized in Table 6. Based upon these estimates, the total association between marital dissatisfaction and maternal negativity was computed as $\mathrm{r}_{\mathrm{est}}=.35$. The parameter estimates in Table 6 were also used to estimate the relative contributions of latent genetic (A1) and nonshared environmental (E1) factors to this association. Based on these computations, genetic factors accounted for $40 \%$ of the association between mothers' marital satisfaction and maternal negativity, and nonshared environmental factors explained the remaining $60 \%$ of the covariance.

Mothers' marital satisfaction and maternal warmth. The AE model yielded a better fit to the data $\left(\chi^{2}(14)=18.67\right.$, AIC $\left.=-9.33\right)$ than the CE model $\left(\chi^{2}(14)=53.64\right.$, AIC $\left.=25.64\right)$. Therefore, the parameter estimates for the AE model are included in Table 6. Based upon these estimates, the association between marriage and parenting was computed as $\mathrm{r}_{\mathrm{est}}=.26$. Slightly more than half of this association $(54 \%)$ was explained by additive genetic factors. The remaining covariance was related to nonshared environmental factors.

Fathers' marital dissatisfaction and paternal negativity. The AE model represented a better fit to the data $\left(\chi^{2}(14)=15.38, \mathrm{AIC}=-12.62\right)$ than the $\mathrm{CE}$ model $\left(\chi^{2}(14)=24.03\right.$, AIC $\left.=-3.97\right)$. The parameter estimates for the AE model are included in Table 7. The association between marriage and parenting was computed as $r_{\text {est }}=.45$. Additive genetic factors explained $44 \%$ of this association, while nonshared environmental factors explained the remaining covariance $(56 \%)$.

Fathers' marital satisfaction and paternal warmth. As in the previous analyses, the fits of the $\mathrm{AE}$ and $\mathrm{CE}$ 
Table 3

Fit indices for the ACE Model and Nested Models for Twin Mothers' Observed Marital Quality and Parenting

\begin{tabular}{|c|c|c|c|c|}
\hline & Model & $d f$ & $\chi^{2}$ & AIC \\
\hline \multirow[t]{4}{*}{ Maternal warmth } & ACE & 3 & 2.07 & -3.93 \\
\hline & $A E$ & 4 & 2.07 & -5.93 \\
\hline & $\mathrm{CE}$ & 4 & 4.28 & -3.72 \\
\hline & $\mathrm{E}$ & 5 & 8.36 & -1.64 \\
\hline \multirow[t]{3}{*}{ Maternal negativity } & ACE & 3 & 0.32 & -5.68 \\
\hline & $\mathrm{AE}$ & 4 & 1.33 & -7.67 \\
\hline & $\mathrm{E}$ & 5 & 11.93 & 1.93 \\
\hline \multirow[t]{4}{*}{ Marital warmth } & ACE & 3 & $9.07^{*}$ & 3.07 \\
\hline & $A E$ & 4 & 9.07 & 1.07 \\
\hline & CE & 4 & $11.87^{*}$ & 3.87 \\
\hline & $\mathrm{E}$ & 5 & $15.68^{*}$ & 5.68 \\
\hline \multirow[t]{4}{*}{ Marital conflict } & ACE & 3 & 3.9 & -2.06 \\
\hline & $\mathrm{AE}$ & 4 & 4.3 & -3.7 \\
\hline & CE & 4 & 3.9 & -4.06 \\
\hline & $E$ & 5 & 4.8 & -5.20 \\
\hline
\end{tabular}

Note: ${ }^{*} p<.05$; The best fitting and most parsimonious models are italicized.

models were compared. Again the AE model yielded a better model fit $\left(\chi^{2}(14)=13.20\right.$, AIC $\left.=-14.80\right)$ than the CE model $\left(\chi^{2}(14)=17.58, \mathrm{AIC}=-10.42\right)$. Therefore, the parameter estimates for the AE model are included in Table 7 . The total correlation between marital satisfaction and paternal warmth was estimated as $\mathrm{r}_{\mathrm{est}}=.25$. Additive genetic factors explained nearly half $(48 \%)$ of this association. Nonshared environmental factors explained the remaining covariance.

\section{Observational Measures}

Observed marital conflict and maternal negativity. The univariate analyses indicated that the best fitting model for marital conflict only included nonshared environmental factors (E) while the best fitting model for maternal negativity included shared (C) and nonshared environmental factors (E). Therefore, the relative fits of the $\mathrm{E}$ and $\mathrm{CE}$ models were compared. The E model yielded an adequate fit to the data $\left(\chi^{2}(17)=22.54\right.$, AIC $\left.=-11.46\right)$. However, the CE model yielded a significantly better fit to the data $\left(\chi^{2}(14)=7.22\right.$, AIC $\left.=-20.78\right)$. The parameter estimates for the CE model are presented in Table 8. The estimated correlation was $r_{\text {est }}=.35$. Sixty-three per cent of the association between observed marital conflict and maternal negativity was explained by nonshared environment factors, while shared environmental factors explained the remainder of this association $(37 \%)$.

Observed marital warmth and observed maternal warmth. Based upon the univariate analyses, an AE model was used to examine the association between marital warmth and maternal warmth. The AE model fit the data well $\left(\chi^{2}(14)=18.01\right.$, AIC $\left.=-9.99\right)$, and the related parameter estimates are included in the bottom of Table 8 . The estimated correlation was $r_{\mathrm{est}}=.42$.
Nonshared environment factors explained $79 \%$ of this association, and additive genetic factors accounted for the remaining $21 \%$ of the association.

\section{Summary}

At the univariate level, nonshared environmental factors accounted for most variance in all of the variables examined. Additive genetic contributions were also present, but were difficult to differentiate from the contributions of shared environmental factors to variance in mothers' and fathers' marital satisfaction, maternal and paternal warmth. However, within the bivariate analyses for the self-report data there was little ambiguity. Additive genetic factors accounted for $40 \%$ to $60 \%$ of the associations between marital quality and parenting variables for both mothers and fathers. The contributions of shared environmental factors to covariance were negligible. In addition, at the bivariate level a greater tendency for genetic factors to explain associations between positive marital and parent-child relationships dimensions than for negative dimensions was not detected. A subset of the female twins was also observed during interactions with their spouses and children. Within the analyses based upon the observational data, genetic factors contributed to associations between positive marital and parenting dimensions, but not negative relationship dimensions. But most of the covariance was explained by nonshared environmental factors.

\section{Discussion}

The current study replicated previous research that detected significant associations between marital and parent-child relationships (Erel \& Burman, 1995; Krishnakumar \& Buehler, 2000). In general, the parents' marital satisfaction was positively related to 
Table 4

Estimated Genetic and Environmental Contributions to Twin Mothers' Observed Parenting and Marital Quality

\begin{tabular}{lccc}
\hline Measure & \multicolumn{3}{c}{ Estimates (CI) } \\
\hline \multicolumn{1}{l}{ Parenting - } & $\mathrm{A}^{2}$ & $\mathrm{C}^{2}$ & $\mathrm{E}^{2}$ \\
observation & & & \\
$\quad$ Warmth & $.18(.04-.31)$ & - & $.82(.69-.96)$ \\
$\quad$ Negativity & - & $.19(.08-.29)$ & $.81(.71-.92)$ \\
Marital quality & & & \\
observation & & - & $.82(.68-.96)$ \\
$\quad$ Marital warmth & $.18(.04-.32)$ & - & $1.0(1.0-1.0)$ \\
$\quad$ Marital conflict & - & - & \\
\hline
\end{tabular}

their self-reported warmth and positivity towards their adolescent children. Conversely, lower marital satisfaction was associated with higher self-reported negativity towards their children. This pattern of findings applied to both mothers and fathers. Female twins in Cohort 1 of TOSS were also observed during interactions with their spouses and with their children. Similar associations were found when the women's observed behaviors were considered. Women who exhibited warmth and support during interactions with their spouses also tended to exhibit warmth and support towards their own children. Similarly, greater marital conflict was related to greater negativity towards the children. Lastly, the magnitude of the correlations obtained from self-report measures was similar to those obtained from observational measures, and similar to those reported in the broader research literature (Erel \& Burman, 1995; Krishnakumar \& Buehler, 2000).

As reported in previous papers, genetic factors explained variance in mothers' and fathers' selfreported marital quality, and parental warmth and negativity (Neiderhiser et al., 2004; Spotts et al., $2005)$. For mothers, genetic contributions to these variables ranged from $32 \%$ to $41 \%$, while for fathers, genetic contributions ranged from $0 \%$ to $45 \%$.
Smaller genetic contributions were detected for observed marital warmth and maternal warmth $(18 \%)$, while genetic contributions were absent for observed marital conflict and maternal negativity. Large nonshared environmental contributions were detected for all dimensions of the marital relationship and parent-child relationship, but were highest for the observational measures.

The finding of greater genetic influences on selfreported phenotypes is not unusual (Loehlin, 1992). However, the reason for this tendency is unclear. One possibility is that observational measures are more susceptible to measurement error. This error may reside in the specific coding schemes selected and in the training of the observers. However, the validity of the coding system used in the current study is well established (Hetherington \& Climgempeel, 1992), and the interrater reliabilities were acceptable. Alternatively, larger nonshared environment contributions to observational measures may indicate that a person's actual behavior is more susceptible to the influences of context than perceptions and beliefs of relationships. For example, when individuals are observed for a brief period of time, as in the case of this study, their behavior at any given moment may be guided or disrupted by specific events or situational demands, making it difficult to discern long-standing patterns of behavior. In contrast, when individuals report on their own behaviors or their relationships, they can reference their histories of interactions, perhaps reducing situational effects on their evaluations and enabling stable genetic influences to be identified.

Within the bivariate analyses additive genetic factors accounted for approximately half of the associations between self-reported marital quality and parenting for both mothers (range $40 \%$ to $56 \%$ ) and fathers (range $44 \%$ to $48 \%$ ). Genetic factors also explained significant covariance between observed measures of marital quality and parenting (range $21 \%$ to $37 \%$ ). Lastly, the contributions of shared environmental factors to covariance were negligible for mothers and fathers. Genetic contributions to this

Table 5

Correlations between Self-Reported and Observed Marital Quality and Parenting for Twin Mothers and Fathers

\begin{tabular}{|c|c|c|c|c|c|c|c|}
\hline & 1 & 2 & 3 & 4 & 5 & 6 & 7 \\
\hline \multicolumn{8}{|l|}{ Self-report measures } \\
\hline Marital satisfaction & - & .25 & -.44 & & & & \\
\hline Parental warmth & .25 & - & .08 & & & & \\
\hline Parental negativity & -.36 & .002 & - & & & & \\
\hline \multicolumn{8}{|c|}{ Observational Measures ${ }^{+}$} \\
\hline Marital conflict & -.34 & -.14 & .11 & - & & & \\
\hline Marital warmth & .19 & .19 & -.01 & -.37 & - & & \\
\hline Maternal warmth & -.02 & .08 & .05 & -.06 & .42 & - & \\
\hline Maternal negativity & -.09 & -.13 & .32 & .34 & -.20 & -.23 & - \\
\hline
\end{tabular}


Table 6

Parameter Estimates and Confidence Intervals (CI) for Associations Between Twin Mothers' Self-Reported Marital Quality and Parenting

\begin{tabular}{|c|c|c|c|c|c|c|}
\hline Variable & Parameter & Estimate (CI) & Parameter & Estimate (CI) & $\chi^{2}$ & AIC \\
\hline \multicolumn{7}{|c|}{ Marital quality and maternal negativity } \\
\hline \multirow[t]{3}{*}{ Marital dissatisfaction } & $a_{11}$ & $.57(.47-.64)$ & & & & \\
\hline & $c_{11}$ & - & & & & \\
\hline & $e_{11}$ & $.82(.77-.88)$ & & & & \\
\hline \multirow[t]{3}{*}{ Maternal negativity } & $a_{12}$ & $.25(.12-.37)$ & $a_{22}$ & $.54(.45-.62)$ & & \\
\hline & $c_{12}$ & - & $c_{22}$ & - & & \\
\hline & $e_{12}$ & $.26(.18-.34)$ & $e_{22}$ & $.76(.70-.82)$ & 17.70 & -10.30 \\
\hline \multicolumn{7}{|c|}{ Marital quality and maternal warmth } \\
\hline \multirow[t]{3}{*}{ Marital satisfaction } & $a_{11}$ & $.57(.47-.65)$ & & & & \\
\hline & $c_{11}$ & - & & & & \\
\hline & $e_{11}$ & $.82(.76-.88)$ & & & & \\
\hline \multirow[t]{3}{*}{ Maternal warmth } & $a_{12}$ & $.24(.11-.36)$ & $a_{22}$ & $.60(.52-.67)$ & & \\
\hline & $c_{12}$ & - & $c_{22}$ & - & & \\
\hline & $e_{12}$ & $.14(.06-.22)$ & $e_{22}$ & $.75(.70-.81)$ & 18.67 & -9.33 \\
\hline
\end{tabular}

Note: $\mathrm{Cl}=95 \%$ Confidence Interval. For all models tested, $d f=14$, and $p>.05$.

covariance could reflect the impact of parents' stable personality characteristics on family relationships. Previous studies have indicated that personality characteristics exhibit moderate heritability (Bouchard \& McGue, 2003), and are associated with marital satisfaction and parenting (Belsky \& Barends, 2002; Jockin et al., 1996). Consistent with this possibility, a previous study with the first cohort of the TOSS data set found that women's personality characteristics partially accounted for genetic contributions to their marital satisfaction (Spotts et al., 2005).

Personality could affect relationships through multiple avenues. For example, genetically influenced personality characteristics could directly affect parents' reactions to interpersonal events as well as their emotion regulatory capacities, regardless of partner. Thus, genetic covariance between the emotional tone of marital and parent-child-relationships may be based in consistencies in the parents' actual behaviors. Yet, the higher genetic contributions to covariance between self-reports of marriage and parenting relative to behavioral observations suggest that other genetically mediated process are operative, but, perhaps, not captured by observational measures. For example, genetically influenced personality characteristics could also affect one's appraisal of relationships. A growing research literature indicates that a person's emotional state can bias their recall and processing of information (Bower, 1981; Forgas, 1994). As such, tendencies towards experiencing negative or positive affective states may influence one's evaluation of relationships, and underlie consistencies in the way relationships are perceived and rated. Consistent with this possibility, neuroticism has been associated with an enhanced capacity to recall unpleasant stimuli and negative personal memories, and poorer accuracy in recalling positive information (DesRosiers \& Robinson, 1992;
Rusting \& Larsen, 1998). Forgas and colleagues (1994) further report that mood states affect evaluations of long-term relationships, especially when asked to reflect upon serious conflicts with partners. Thus, it is plausible that genetic contributions to covariance between relationships are based in parents' actual behaviors as well as biases in the ways interpersonal experiences are recalled and processed.

The current study also examined whether genetic factors contribute to positive relationship dimensions more consistently than negative dimensions. We did not find support for this pattern amongst the selfreport data for mothers and fathers. Genetic contributions were comparable for positive and negative relationship dimensions, and to associations between different relationships. Within the observational data set, genetic contributions were significant for positive relationship dimensions, but not for negative dimensions. However, it is important to note that the genetic contributions to the positive dimensions were low. Consequently, there may be greater genetic influences on the expression of positive affect than negative affect within relationships, but this difference is small.

Although we have highlighted the contributions of genetic factors to associations between marital and mother-child relationships, it is also important to keep in mind that nonshared environmental factors explained most of the variance in the parenting and marital relationship measures, as well as associations between these measures. Consequently, the twins' unique experiences represent stronger influences on the emotional quality of relationships than genetic factors. The specific experiences that underlie these differences were not identified by this study. However, one strong possibility is that a unique emotional climate evolves within a family and influences all 
Table 7

Parameter Estimates and Confidence Intervals (CI) for Associations between Twin Fathers' Self-Reported Marital Quality and Parenting

\begin{tabular}{|c|c|c|c|c|c|c|}
\hline Variable & Parameter & Estimate (CI) & Parameter & Estimate (CI) & $\chi^{2}$ & AIC \\
\hline \multicolumn{7}{|c|}{ Marital quality and paternal negativity } \\
\hline \multirow[t]{3}{*}{ Marital dissatisfaction } & $a_{11}$ & $.48(.29-.61)$ & & & & \\
\hline & $c_{11}$ & - & & & & \\
\hline & $e_{11}$ & $.88(.79-.96)$ & & & & \\
\hline \multirow[t]{3}{*}{ Paternal negativity } & $a_{12}$ & $.41(.21-.61)$ & $a_{22}$ & $.53(.31-.64)$ & & \\
\hline & $c_{12}$ & - & $c_{22}$ & - & & \\
\hline & $e_{12}$ & $.28(.17-.38)$ & $e_{22}$ & $.69(.62-.77)$ & 15.38 & -12.62 \\
\hline \multicolumn{7}{|c|}{ Marital quality and paternal warmth } \\
\hline \multirow[t]{3}{*}{ Marital satisfaction } & $a_{11}$ & $.48(.28-.61)$ & & & & \\
\hline & $c_{11}$ & - & & & & \\
\hline & $e_{11}$ & $.88(.80-.96)$ & & & & \\
\hline \multirow[t]{3}{*}{ Paternal warmth } & $a_{12}$ & $.25(.03-.48)$ & $a_{22}$ & $.56(.38-.67)$ & & \\
\hline & $c_{12}$ & - & $c_{22}$ & - & & \\
\hline & $e_{12}$ & $.15(.03-.26)$ & $e_{22}$ & $.77(.70-.85)$ & 13.20 & -14.80 \\
\hline
\end{tabular}

Note: $\mathrm{Cl}=95 \%$ Confidence Interval. For all models tested, $d f=14$, and $p>.05$.

relationships within it (Cox \& Paley, 1997). This interpretation is consistent with the findings of the Nonshared Environment and Adolescent Development (NEAD) project, which examined the contributions of child-based genetic and environmental factors to parenting (Reiss et al., 2000). Within NEAD, siblings' shared experiences accounted for significant variance in parental warmth and negativity. This finding does suggest that there is a family-wide emotional climate that underlies similarities in the way in which different family members relate to each other, and emotional convergence across family relationships.

The developmental literature has offered several detailed accounts of how such a family climate may evolve. Conflictual or dissatisfying marital relationships may cause parenting to deteriorate because marital stress drains parents' emotional energy, drawing their attention away from their children, and reducing their capacities to respond sensitively to their children (Easterbrooks \& Emde, 1988; Kitzmann, 2000; Margolin et al., 1996). When this occurs, conflict and negative affect will seem to pervade all family subsystems, creating a general emotional climate within the family. It is important to note that conflict or warmth within parent-child interactions can also spill over to and affect the marital relationship (Almeida et al., 1999). In some cases attributes of the child or transitions in the parent-child relationship may also place stress on the marital relationship (Cox \& Paley, 1997). As such, children's characteristics can contribute to the overall emotional climate of the family, and within the context of the current study, explain nonshared environmental influences.

In summary, previous studies have identified significant associations between marital quality and parenting. In most cases environmentally based causal mechanisms are used to explain these associations, for example, conflict in the marital relationship causes deterioration in parenting or emotions that arise in the marital relationship are not contained, and literally spill over to the parent-child relationship. This study, however, found evidence of parent-based genetic and environmental contributions to associations between marital quality and maternal negativity and warmth. These findings highlight the unique contributions of parents' genetically influenced characteristics to consistencies in the affective tone across family subsystems, while also acknowledging the role of the environment in shaping family relationships. Therefore, a key implication of the current study is that associations between family subsystems are not entirely causally related nor explained by environmental mechanisms. This finding reestablishes the importance of understanding the role of the individual in shaping the emotional climate of the family, and the mechanisms through which this achieved. An important clinical implication of this finding is that marital interventions should not only focus upon the specific behavioral patterns of couples, but also the degree to which stable personality characteristics help perpetuate such patterns within the marital relationship and across different family relationships.

These findings, however, should not be viewed as undermining family systems theories which emphasize environmental mechanisms in understanding the impact of different family relationships on each other (Cox \& Paley, 1997). Consistent with this set of theories, the current study also found that much of the covariance between marital quality and parenting was related to nonshared environmental factors. Thus, although parents' genetically influenced characteristics contribute to the functioning of family subsystems, the environment accounts for most variance within each subsystem and covariance between them. 
Table 8

Parameter Estimates and Confidence Intervals (CI) for Associations between Twin Mothers' Observed Marital Quality and Parenting

\begin{tabular}{|c|c|c|c|c|c|c|}
\hline Variable & Parameter & Estimate (CI) & Parameter & Estimate (CI) & $\chi^{2}$ & AIC \\
\hline \multicolumn{7}{|c|}{ Marital conflict and maternal negativity } \\
\hline \multirow[t]{3}{*}{ Marital conflict } & $a_{11}$ & - & & & & \\
\hline & $c_{11}$ & $.29(.14-.42)$ & & & & \\
\hline & $e_{11}$ & $.96(.91-.99)$ & & & & \\
\hline \multirow[t]{3}{*}{ Maternal negativity } & $a_{12}$ & - & $a_{22}$ & - & & \\
\hline & $c_{12}$ & $.44(.26-.54)$ & $c_{22}$ & $.00(.00-.34)$ & & \\
\hline & $e_{12}$ & $.23(.14-.31)$ & $e_{22}$ & $.87(.81-.92)$ & 7.22 & -20.78 \\
\hline \multicolumn{7}{|c|}{ Marital warmth and maternal warmth } \\
\hline \multirow[t]{3}{*}{ Marital warmth } & $a_{11}$ & $.43(.21-.56)$ & & & & \\
\hline & $c_{11}$ & - & & & & \\
\hline & $e_{11}$ & $.90(.83-.98)$ & & & & \\
\hline \multirow[t]{3}{*}{ Maternal warmth } & $a_{12}$ & $.21(.00-.42)$ & $a_{22}$ & $.37(.13-.50)$ & & \\
\hline & $c_{12}$ & - & $c_{22}$ & - & & \\
\hline & $e_{12}$ & $.37(.26-.48)$ & $e_{22}$ & $.83(.75-.90)$ & 18.01 & -9.99 \\
\hline
\end{tabular}

Note: $\mathrm{Cl}=95 \%$ Confidence Interval. For all models tested, $d f=14$, and $p>.05$.

As in any study, the current study had limitations that should be considered. One potential limitation is our decision to explore the contributions of additive genetic rather than nonadditive genetic factors. The underlying rationale for this decision was that twin studies have very low power to disentangle additive and dominant genetic effects (Neale \& Cardon, 1992). In the absence of shared environmental effects, any increase in similarity above additive genetic effects between $\mathrm{MZ}$ twins as compared to $\mathrm{DZ}$ twins would be identified as dominant genetic effects, regardless if this occurred by chance (which will happen in $50 \%$ of the cases) or because there are true dominant effects. Thus, if there are true dominant effects, they would have been encompassed within estimates of the additive genetic parameter. However, the interpretation of the results will be the same regardless if there are true dominant genetic effects or not.

A second potential limitation concerns the Cholesky model. A Cholesky model was selected to assess associations between marital quality and parenting for theoretical reasons. However, a recent paper has raised questions about comparing the relative fits of nested models (Carey, 2005). Difficulties arise when an estimated pathway is close to zero, and potentially functions as a 'fixed' parameter. When this occurs, Cholesky models sometimes produce fit statistics that are not distributed as chi-square values, and the degrees of freedom are not always the difference between the number of parameters in the general model and the constrained model (Carey, 2005). In this paper, we have focused on the covariance between our measures, and the resulting analyses may not be affected by this problem. Nevertheless, Carey (2005) raises important questions regarding how the relative fit of nested models should be tested, necessitating caution in interpreting the results of analyses based upon the Cholesky model.

Other limitations center upon understanding specific sources of genetic and nonshared environmental contributions to covariance between marital quality and parenting. The current study did not identify nor test hypotheses regarding specific characteristics of the twins or their families that could account for these effects. Previous phenotypic studies indicate that neuroticism, depression, extraversion, and ego-control are all associated with marital quality (e.g., Jockin et al., 1996) and with parenting (e.g., Belsky \& Barend, 2002). These characteristics are associated with how parents respond to each other, the emotional tone of interactions, and as described previously, with the appraisal of relationships. Consequently, future analyses need to examine whether these stable behavioral tendencies mediate genetic influences on marriage and parenting, as well as covariance between these family subsystems.

Differences in the quality of the twins' relationships within their families could also reflect the influence of their children's and spouses' personality characteristics. Within TOSS the personalities of other family members provide the context for marital and parenting interactions, and are probably significant sources of nonshared environmental influences on the quality of these relationships, and covariance between them. Consistent with this latter explanation, findings from the child-based NEAD study indicate that parenting and interparental conflict over parenting issues are significantly influenced by child-based genetic factors (Reiss et al., 2000). Moreover, as discussed previously, an additional source of nonshared environmental influences within TOSS could be the general family climate. This latter hypothesis could be tested by examining if family-wide evaluations of conflict 
and warmth account for significant covariance between marriage and parenting.

Lastly, the current study simply tested whether marital quality and parenting are linked by latent genetic and environmental factors. However, it is probable that marriage and parenting are related in more complex ways that were not tested in this paper. For example, it is possible that environmental and genetic mechanisms moderate the effects of each other. Specifically, the spill over of negative affect across relationships may be enhanced when genetically influenced characteristics such as heightened neuroticism are present, or diminished in the presence of positive characteristics such as optimism or cooperativeness. Likewise, genetically-influenced vulnerabilities such as depression may make some individuals more susceptible to parenting deterioration following marital strife (Davies et al., 2004). Consequently, much research is still needed to understand how and why relationships within a family influence each other. Additional behavioral genetics research will be instrumental in expanding our knowledge of the underlying mechanisms.

\section{Acknowledgments}

The Twin and Offspring Study in Sweden was supported by the National Institute of Mental Health (NIMH) Grant R01MH54601 (PI: Reiss - Cohort 1; PI: Neiderhiser - Cohort 2).

The authors acknowledge funding support from the National Institute on Aging. The views expressed are those of the authors of this paper, and not the National Institute on Aging, the National Institutes of Health or the Department of Health and Human Services.

\section{References}

Almeida, D. M., Wethington, E., \& Chandler, A. L. (1999). Daily transmission of tensions between marital dyads and parent-child dyads. Journal of Marriage and the Family, 61, 49-61.

Belsky, J., \& Barends, M. (2002). Personality and parenting. In M. H. Bornstein (Ed.), Handbook of parenting, Vol. 2 (pp. 415-438). Mahwah, New Jersey: Lawrence Erlbaum Associates, Publishers.

Booth, A., Johnson, D., \& Edwards, J. N. (1983). Measuring marital instability. Journal of Marriage and the Family, 45, 387-394.

Bouchard, T., \& McGue, M. (2003). Genetic and environmental influences on human psychological differences. Journal of Neurobiology, 54, 4-45.

Bower, G. (1981). Mood and memory. American Psychologist, 36, 129-148.

Carey, G. (2005). Cholesky problems. Behavior Genetics, 35, 653-665.

Cox, M. J., \& Paley, B. (1997). Families as systems. Annual Review of Psychology, 48, 243-267.
Davies, P. T., Sturge-Apple, M. L., \& Cummings, E. M. (2004). Interdependencies among interparental discord and parenting practices: the role of adult vulnerability and relationship perturbations. Development and Psychopathology, 16, 773-797.

DesRosiers, G., \& Robinson, D. (1992). Memory and hedonic tone: 'Personality' or 'mood' congruence? Psychological Medicine, 22, 117-129.

Easterbrooks, M.A., \& Emde, R.N. (1988). Marital and parent-child relationships: The role of affect in the family system. In R. A. Hinde \& J. S. Hinde (Eds.), Relationships within families: Mutual influences (pp. 83-103). New York: Oxford University Press.

Eaves, L. J., Silberg, J. L., Meyer, J. M., Maes, H. H., Simonoff, E., Pickles, A., Rutter, M., Neale, M. C., Reynolds, C. A., Erikson, M. T., Heath, A. C., Loeber, R., Truett, K. R., \& Hewitt, J. K. (1997). Genetics and developmental psychopathology: 2 . The main effects of genes and environment on behavioral problems in the Virginia Twin Study of Adolescent Behavioral Development. Journal of Child Psychiatry and Psychology and Allied Disciplines, 38, 965-980.

Erel, O., \& Burman, B. (1995). Interrelatedness of marital relations and parent-child relations: A meta-analytic review. Psychological Bulletin, 118, 108-132.

Forgas, J. P. (1994). Sad and guilty? Affective influences on the explanation of conflict episodes. Journal of Personality and Social Psychology, 66, 56-68.

Forgas, J. P., Levinger, G., \& Moylan, S. (1994). Feeling good and feeling close: Affective influences on the perception of intimate relationships. Personal Relationships, 1, 165-184.

Hansson, K., \& Jarbin, G. (1997). A new self-rating questionnaire in Swedish for measuring expressed emotion. Nordic Journal of Psychiatry, 51, 287-297.

Hetherington, E. M., \& Clingempeel, G. W. (1992). Coping with marital transitions: A family systems perspective. Monographs of the Society for Research in Child Development, 57, 1-242.

Hetherington, E. M., Hagan, M. S., \& Eisenberg, M. (1992). Family interaction coding system. Unpublished manuscript.

Jockin, V., McGue, M., \& Lykken, D.T. (1996). Personality and divorce: A genetic analysis. Journal of Personality and Social Psychology, 71, 288-299.

Kaslow, F. W., Hansson, K., \& Lundblad, A. (1994). Long-term marriages in Sweden. Some comparisons with similar couples in the United States. Contemporary Family Therapy, 18, 521-537.

Kendler, K. S. (1996). Parenting: A genetic-epidemiologic perspective. American Journal of Psychiatry, 153, 11-20.

Kitzmann, K. (2000). Effects of marital conflict on subsequent triadic family interactions and parenting. Developmental Psychology, 36, 3-13.

Kochanska, G., Friesenborg, A. E., Lange, L. A., \& Martel, M. M. (2004). Parents' personality and 
infants' temperament as contributors to their emerging relationship. Journal of Personality and Social Psychology, 86, 744-759.

Krishnakumar, A., \& Buehler, C. (2000). Interparental conflict and parenting behaviors: A meta-analytic review. Family Relations, 49, 25-441.

Lichtenstein, P., De Faire, U., Floderus, B., Svartengren, M., Svedberg, P., \& Pedersen, N. L. (2002). The Swedish Twin Registry: A unique resource for clinical, epidemiological and genetic studies. Journal of Internal Medicine, 252, 184-205.

Loehlin, J. (1992). Genes and environment in personality development. Newbury Park, CA: Sage.

Losoya, S. H., Callor, S., Rowe, D. C., \& Goldsmith, H. H. (1997). Origins of familial similarity in parenting: a study of twins and adoptive siblings. Developmental Psychology, 33, 1012-1023.

Margolin, G., Christensen, A., \& John, R.S. (1996). The continuance and spill over of everyday tensions in distressed and nondistressed families. Journal of Family Psychology, 10, 304-321.

McGue, M., \& Bouchard, T. J. (1984). Adjustment of twin data for the effects of age and sex. Behavior Genetics, 14, 325-343.

Mulaik, S. A., James, L. R., Alstine, J. V., Bennett, N., Lind, S., \& Stilwell, C. D. (1989). Evaluation of goodness-of-fit indices for structural equation models. Psychological Bulletin, 105, 430-445.

Neale, M. C. (2000). Mx: Statistical modeling. Richmond, VA: Department of Psychiatry.

Neale, M. C., \& Cardon, L. R. (1992). Methodology for genetic studies of twins and families. Boston: Kluwer Academic.

Neiderhiser, J. M., Reiss, D., Pedersen, N. L., Lichtenstein, P., Spotts, E. L., Hansson, K., Cederblad, M., \& Elthammer, O. (2004). Genetic and environmental influences on mothering of adolescents: A comparison of two samples. Developmental Psychology, 40, 335-351.

Perusse, D., Neale, M. C., Heath, A. C., \& Eaves, L. J. (1994). Human parental behavior: Evidence for genetic influence and potential implication for gene-culture transmission. Behavior Genetics, 24, 327-335.
Reiss, D., Neiderhiser, J. M., Hetherington, E. M., \& Plomin, R. (2000). The relationship code. Cambridge, MA: Harvard University Press.

Reiss, D., Pedersen, N. L., Cederblad, M., Lichtenstein, P., Hansson, K., Neiderhiser, J. M., \& Elthammar O. (2001). Genetic probes of three theories of maternal adjustment: I. Recent evidence and a model. Family Process, 40, 247-259.

Rusting, C. L., \& Larsen, R. J. (1998). Personality and cognitive processing of affective information. Personality and Social Psychology Bulletin, 24, 200-213.

Spanier, G. B. (1976). Measuring dyadic adjustment: New scales for assessing quality of marriage and similar dyads. Journal of Marriage and the Family, 38, 15-28.

Spinath, F. M., \& O’Connor, T. G. (2003). A behavioral genetic study of the overlap between personality and parenting. Journal of Personality, 71, 785-808.

Spotts, E. L., Lichtenstein, P., Pedersen, N., Neiderhiser, J. M., Hansson, K., Cederblad, M., \& Reiss, D. (2005). Personality and marital satisfaction: A behavioural genetic analysis. European Journal of Personality, 19, 205-227.

Spotts, E. L., Neiderhiser, J. M., Towers, H. , Hansson, K, Lichenstein, P., Cederblad, M., Pedersen, N., \& Reiss, D. (2004). Genetic and environmental influences on marital relationships. Journal of Family Psychology, 18, 107-119.

Tanaka, J. S. (1993). Multifaceted conceptions of fit in structural equation modelling. In K. A. Bollen \& J. S. Long (Eds.), Testing structural equation models (pp. 10-39). Thousand Oaks, CA: Sage.

Towers, H., Spotts, E. L., \& Neiderhiser, J. M. (2001). Genetic and environmental influences on parenting and marital relationships: Current findings and future directions. Marriage and Family Review, 33, 11-29.

Trumbetta, S. L., \& Gottesman, I. I. (2000). Endophenotypes for marital status in the NAS-NRC twin registry. In J. L. Rogers \& D .C. Rowe (Eds.), Genetic influences on human fertility and sexuality (pp. 253-269). Boston: Kluwer Academic Publisher

Ulbricht, J., Ganiban, J. M., \& Neiderhiser, J. M. (2006, March). Parenting and personality. Poster presented at the Biennial Meeting of the Society for Research on Adolescence, San Francisco, CA. 